\title{
Manual therapy and barefoot run training in the treatment of a fibular stress fracture in a marathon runner: A case report
}

\author{
Brett B. Clark*
}

School of Medicine, Department of Anatomy and Neurobiology, University of Maryland, Baltimore, USA²Division of Plastic and Reconstructive Surgery, Department of Surgery, Medical University of Vienna, Austria

\begin{abstract}
Background: Manual therapy is a commonly used treatment modality. Its effectiveness has been described in the literature, though there is sparse evidence regarding manual therapy and lower extremity dysfunction as it pertains to distance runners. Barefoot run training has gained recent popularity and has been used in prevention of injury by improving run technique.

Case description: We report the case of a 29 y.o. female who presented to physical therapy 4 weeks after diagnosis of stress fracture and 6 weeks before participating in the Chicago Marathon. After 6 weeks of manual therapy and barefoot run training, she was able to complete the Chicago Marathon in her goal time.

Purpose and clinical relevance: This case demonstrates a novel treatment approach combining manual therapy and barefoot run training without cessation of running in rehabilitation of a fibular stress fracture.
\end{abstract}

\section{Introduction}

The ability to run 26.2 miles is dependent on a number of factors. Remaining free of injury during training is certainly one of them. The training volume that is necessary to complete this grueling test of endurance places the athlete at increased risk of injury [1]. Injury risk is strongly associated with running volume [2]. The incidence of injuries in recreational runners has been reported to be 37 to $56 \%$ [3], with the bones and joints of the foot and ankle being most at risk [2]. During running, the body experiences vertical forces between 2.5 and 2.8 times body weight [4], placing great stress on the soft tissues of the lower extremities. Improper attenuation of these forces coupled with increased training volume can lead to stress fractures [5]. Stress fractures account for $50 \%$ of running injuries [6]. The incidence of stress fracture in distance running has been reported to be as high as $31 \%$ [7]. Women are at a significantly greater risk, especially if they are amenorrheic or have eating disorders [8].

It is felt that stress fractures are related to the impact forces and loading rates suffered by the foot and lower extremities during running [9]. These forces are transmitted through the foot and ankle and are absorbed by the soft tissues and bones of the lower extremities. The total range of motion the lower extremity undergoes during the gait cycle may influence the forces experienced by the body [9]. Greater range of motion results in lower peak ground reaction forces and thus lower loading rates. Inadequate ankle flexibility has been shown to increase risk of stress fractures [10].

Inadequate joint mobility can lead to impaired running mechanics as compensations will occur proximally to compensate for faulty foot and ankle mechanics [11]. Reduced ankle mobility causes increased lower extremity stiffness and reduced shock attenuation [5]. Normal joint mobility at the sub-talar and talocrural joints allows for pronation and supination of the foot during the gait cycle [11]. Inadequate pronation and supination of the foot can reduce stability and produce trauma to the foot, and through a closed kinetic chain, the resultant forces are transmitted to the leg, knees and hips [12].

In an effort, to reduce some of the impact force and support the foot, the running shoe was introduced. Over the years, running shoes have evolved to be specific to foot type as models are available for those who pronated, neutral or supinated feet. Interestingly, though, one study indicates that perhaps the running shoes themselves may be a culprit in injury production [13]. Despite the advances in running shoe technology, the rate of injury in distance running remains very high. Thus, runners have sought numerous strategies in hopes of reducing injury and running faster. One such strategy is running without any shoes at all [14].

Barefoot running has been shown to improve run technique and even prevent injury [15]. More and more running shoe companies are developing minimalist shoe offerings as the traditional running shoe has been shown to encourage heel strike, thus increasing injury risk [16]. Inducing heel strike creates a braking action each time the foot makes initial contact, thus increasing the stresses born by the lower extremity [17]. Though gaining popularity in running circles, there is

Correspondence to: Brett B. Clark PT, DPT, School of Medicine, Department of Anatomy and Neurobiology, University of Maryland, Baltimore, USA, E-mail: bclark@lifestrengthpt.com

Key words: Imanual therapy, stress fracture, barefoot running, marathon

Received: May 22, 2017; Accepted: June 08, 2017; Published: June 11, 2017 
no literature reporting barefoot run training as a treatment modality. Not considered a traditional physical therapy treatment modality, we have been employing these techniques, and elements of barefoot running to assist runners in developing improved running form as they recover from injury, as opposed to before injury occurs or after the injury has healed.

Although important, simply changing running form may not be sufficient to fully rehabilitate one from injury or prevent re-injury. As mentioned earlier, deficiencies in joint mobility or muscle performance can be contributing factors to injury. Further examination of these deficiencies is necessary in order to fully rehabilitate the running athlete.

Joint mobility testing is one of many examination techniques employed by physical therapists [18]. Once restrictions of joint mobility have been identified, joint mobilization or manipulation techniques are employed to correct these limitations [18]. The use of manipulation in physical therapy has been well documented in the literature for many years [19]. In particular, joint mobilization has been shown to be effective in correcting lower extremity joint dysfunction and normalizing joint mobility [20,21]. Joint mobilization has been shown to be more effective than exercise alone or placebo and joint mobilization combined with exercise therapy has been shown to be highly effective in correcting lower extremity dysfunction [22].

The purpose of this case study was to describe the unique combination of a well-established treatment modality, manipulation, with a novel modality, or form of exercise training, barefoot running, and its effectiveness in rehabilitating a marathon runner that had been diagnosed with a fibular stress fracture.

\section{Case report}

\section{History}

A 29-year-old female runner was seen to evaluate left lower extremity and foot pain with running. She was referred to our office by a local running store, not by physician referral. The patient was training for her first marathon and was 10 weeks into a 16-week training plan.

Four weeks prior to reporting to physical therapy, she was diagnosed with a fibular stress fracture. She refrained from running for 2 weeks after diagnosis. Physician recommendation was 6 weeks. She resumed running at reduced mileage 2 weeks prior to initiating physical therapy, 4 weeks after diagnosis.

Past medical history was negative for prior lower extremity injury and was unremarkable for any medical issues. The patient was not taking any medications, but was using ice 3 times daily for 15 minutes to control pain. Weekly running mileage was 8 miles, down from peak of 40 miles at time of injury. The patient had completed one long run of 16 miles prior to injury.

Interestingly, the patient's chief complaint at time of initial evaluation was mainly lateral foot pain with running (4/10) and very mild lateral leg pain (2/10). The patient reported being able to run up to 2 miles at $50 \%$ effort prior to onset of pain at time of initial evaluation. General medical questionnaire was negative for suspicion of any sinister pathology. The patient also denied any history of amenorrhea or eating disorders. The patient was working full-time as a project manager and had no limitations in ability to perform work tasks.

\section{Review of systems}

\begin{tabular}{|c|c|}
\hline $\begin{array}{l}\text { Cardiovascular and } \\
\text { Pulmonary System }\end{array}$ & Musculoskeletal System \\
\hline 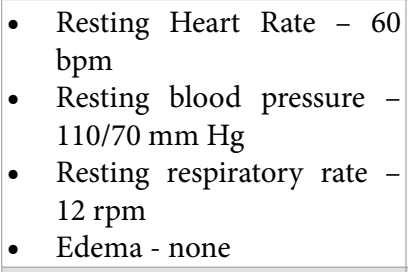 & $\begin{array}{l}\text { - Symmetry - no deficits noted } \\
\text { limitations in left ankle DF and } \\
\text { EV } \\
\text { - Gross strength - WNL } \\
\text { - Height }-5{ }^{\prime \prime} \text { " Weight }-130 \mathrm{lbs}\end{array}$ \\
\hline Neuromuscular System & Integumentary System \\
\hline $\begin{array}{ll}\text { - } & \text { Gait- slight discomfort } \\
\text { - } & \text { Locomotion/mobility } \\
\text { Antalgic gait on Left } \\
\text { - } & \text { Balance - Normal } \\
\text { - Transfers - no deficit }\end{array}$ & $\begin{array}{ll}\text { - } & \text { Integrity - Intact } \\
\text { - } & \text { Color - Normal } \\
\text { - Scars - None }\end{array}$ \\
\hline
\end{tabular}

\section{Physical exam}

The patient presented with antalgic gait demonstrating decreased stance time on the left and reduced step length on the right. Running gait performed on a treadmill at $6.0 \mathrm{mph}$ (patient's self-selected comfortable running pace) at $1 \%$ grade revealed reduced cadence of 78 strides/minute and significant reduction in left stance time, as well as decreased push-off on the left during terminal stance. Additionally, the patient exhibited pronounced heel striking bilaterally during initial contact.

The patient exhibited a 12 degree decrease in dorsiflexion range of motion when measured in knee flexion and extension as compared to the uninvolved side and a 10 degree reduction in eversion. Sub-talar neutral was maintained during dorsiflexion range of motion measurements by palpating the medial and lateral talar head and maintaining the position of the talus where each side was palpated equally. Range of motion measurements were taken using an inclinometer (Figures 1A and 1B) which demonstrates ICC values of .90-.98 for dorsiflexion and .89-.97 for sub-talar eversion. This method was chosen over traditional goniometry as we felt this was a more reliable measure of range of motion as ICC measurements for dorsiflexion and eversion using a plastic goniometer were .90 and .59 respectively [23].

The photographs show the method used for measuring ankle range of motion. Figure 1A demonstrates the method used for measuring dorsiflexion and $1 \mathrm{~B}$ for eversion.

Manual muscle testing, performed as described by Kendall [24], revealed 5/5 strength for plantarflexion, dorsiflexion, inversion and eversion without pain.

Joint mobility testing, as described by Maitland [25] (Figure 2) revealed significant restrictions in sub-talar mobility, more specifically, in lateral gliding and moderate restrictions in posterior talocrural mobility.

This image shows the technique used to assess for talocrural and sub-talar mobility.

Single leg stance time was reduced to 5 seconds due to instability and pain. To assess single leg stance, the patient was instructed to stand on one foot, without shoes on, with contralateral leg bent and not touching the tested limb. Single leg balance test has shown high reliability when tested using healthy athletes as a measure of proprioceptive ability and balance [23]. 

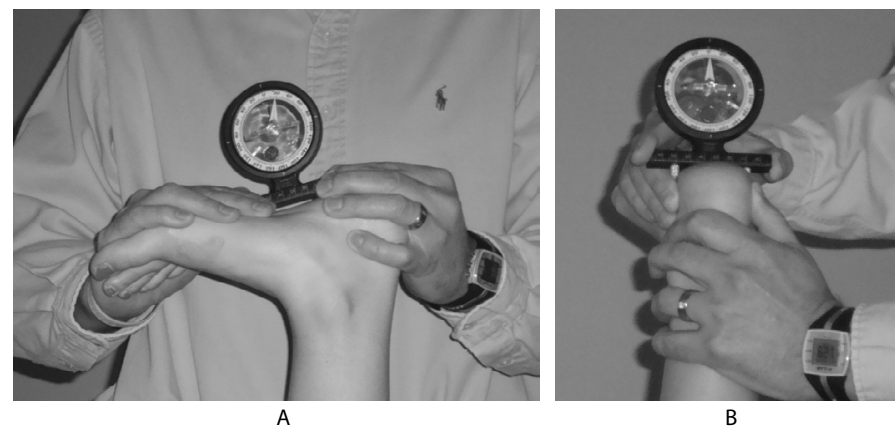

Figures 1A and 1B. Eversion and dorsiflexion range of motion measurement using inclinometer.

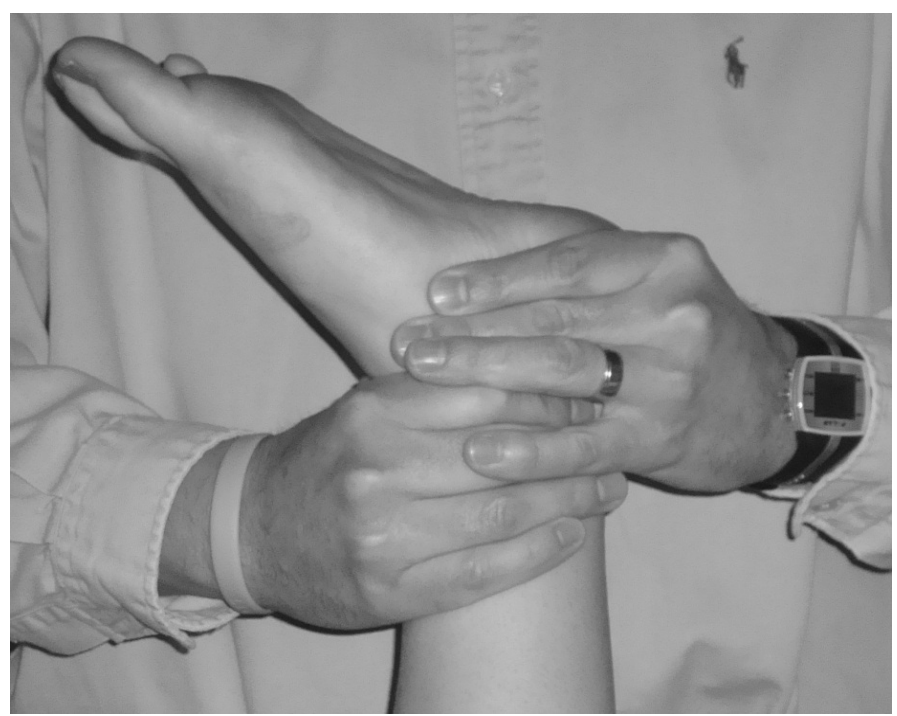

Figure 2. Joint Mobility Testing.

During functional testing, the patient exhibited the ability to squat with little pain, however, based on visual inspection, compensated on the left with hip abduction due to reduction in left ankle dorsiflexion and left lateral foot pain. The patient was unable to perform single leg hop due to pain in the lateral foot upon attempts.

Tissue texture abnormalities and tenderness were elicited with palpation of the lateral aspect of the plantar surface of the left foot in the area of the long plantar ligament. Additionally, there was mild $(2 / 10)$ pain in the distal aspect of the fibula, approximately 1 " superior to the lateral malleolus with vigorous tapping of the fibular shaft.

Vibration testing using a tuning fork at $128 \mathrm{hx}$, which has been shown to be sensitive to distal fibular fracture [26] was used to help loosely ascertain the status of the fracture. This test elicited no pain when performed along several points on the shaft of the fibula approximately $3 \mathrm{~cm}$ apart and encompassing the entire length of the fibula.

The patient scored $46 / 80$ on the Lower Extremity Functional Scale (LEFS). The LEFS was developed in 1999 to provide a functional measure that was easy to administer and score and applicable to a wide range of patients with lower-extremity orthopedic conditions [27]. We have used this measure extensively in our practice and chose this measure given its ease of administration and high test-retest reliability, with an ICC of .92 [23].

\section{Evaluation/diagnosis}

The medical diagnosis given to this patient was fibular stress fracture, based on $\mathrm{x}$-rays taken at the time of her visit to her primary care physician. The physician felt that the site of the fracture was very focal and that the fracture was caught very early. He did not feel there was a need to perform other diagnostic tests such as bone scan or MRI. The physical therapy diagnosis, based on classifications in The Guide to Physical Therapist Practice [18], was Musculoskeletal Pattern G. The Guide divides preferred practice patterns into 4 separate categories: Musculoskeletal, Neuromuscular, Cardiovascular/Pulmonary and Integumentary [18]. Pattern G is "Impaired Joint Mobility, Muscle Performance, and Range of Motion Associated with Fracture. Given the medical diagnosis of fibular stress fracture and the range of motion limitations observed in the examination, coupled with the impact on the patient's ability to run, this seemed to be the most appropriate physical therapy diagnosis.

\section{Intervention}

The patient was seen for a total of 5 visits at a frequency of $1 \mathrm{x} / \mathrm{wk}$ over a 5-week period. Treatment sessions were 30 minutes in length with treatment sessions comprised of 25 minutes of lateral sub-talar mobilization at grade III, and posterior talocrural mobilization at grade III/IV, using Maitland's definition of mobilization grading and mobilization technique [25]. The remaining treatment time was used for home exercise prescription and progression.

Home exercises were performed at a local running track and were performed as illustrated in Table 2. Exercises were advanced each visit. Prior to performing exercises listed in the home exercise program, the patient was instructed in proper technique to ensure proper performance and to be sure that she was able to perform them without pain. The patient was formally re-assessed at visit 3 and 5 (Table 1).

The patient was given explicit instruction that if pain increased at any time during her training she was to stop immediately. We also explained to her that if pain prevented her from advancing from one level in the exercise prescription to the next, she would not be able to participate in the marathon.

Given the medical diagnosis of fibular stress fracture we felt it was extremely important to address running technique to not only reduce the risk of further injury, but to prevent recurrence. Although rest is the most commonly prescribed medical advice in stress fracture [28], our patient was unwilling to adhere to these recommendations as completing the marathon was a very large personal goal. Given that the fibula bears only $6-17 \%$ of body weight $[29,30]$, and the fact that the

Table 1. Assessment results from visit 1,3, 5. This table illustrates the improvements made in objective measures from visits 1-5.

\begin{tabular}{|c|c|c|c|}
\hline Objective Measures & Visit 1 & Visit 3 & Visit 5 \\
\hline $\begin{array}{c}\text { Running cadence } \\
\text { (strides/min) }\end{array}$ & 78 & 83 & 86 \\
\hline LEFS score* & 46 & 67 & 80 \\
\hline $\begin{array}{c}\text { DF ROM+ (deg.) } \\
\text { (compared to uninv.) }\end{array}$ & -12 & -4 & Equal to uninvolved \\
\hline $\begin{array}{c}\text { EV ROM++ (deg.) } \\
\text { (compared to uninv.) }\end{array}$ & -10 & -4 & Equal to uninvolved \\
\hline Pain with palpation & 2 & 1 & 0 \\
\hline $\begin{array}{c}\text { Single leg stance } \\
\text { time (in seconds) }\end{array}$ & 5 & 17 & 60 \\
\hline
\end{tabular}

*Lower Extremity Functional Scale ( 80 is maximum score)

+ Dorsiflexion range of motion

++ Eversion range of motion 
Table 2. Home exercise prescription. This table demonstrates the home exercise prescription and progressions that the patient performed during her rehabilitation.

\begin{tabular}{|c|c|c|c|c|c|}
\hline Exercise Prescription & Visit 1 & Visit 2 & Visit 3 & Visit 4 & Visit 5 \\
\hline $\begin{array}{l}\text { Barefoot Run Training* } \\
\text { (performed at track) }\end{array}$ & $\begin{array}{l}\text { Run straights and walk } \\
\text { curves. } 4 \text { reps. ( } 2 \text { laps of } \\
\text { track) Mon. and Thurs. }\end{array}$ & $\begin{array}{l}\text { Run straights and walk } \\
\text { curves. } 8 \text { reps. ( } 4 \text { laps) } \\
\text { Mon. and Thurs. }\end{array}$ & $\begin{array}{l}\text { Run straights and walk } \\
\text { curves. } 12 \text { reps ( } 6 \text { laps) } \\
\text { Tues. and Friday }\end{array}$ & $\begin{array}{l}\text { Run } 1 \text { lap/walk } 1 / 2 \text { lap. } \\
\text { Repeat x } 4 \text {. Tues. and Friday }\end{array}$ & $\begin{array}{l}\text { Run } 100 \text { meters x } 4 \text { after } \\
\text { weekday runs on Mon. and } \\
\text { Thurs. }\end{array}$ \\
\hline Therapeutic Exercise & $\begin{array}{l}\text { 1. Standing DF stretch }-30 \\
\text { sec. } x 2 \text { daily } \\
\text { 2. Eversion stretch using strap } \\
-30 \text { sec. } x 2 \text { daily }\end{array}$ & $\begin{array}{l}\text { 1. Standing DF stretch }-45 \\
\text { sec. } x 2 \text { daily } \\
\text { 2. Eversion stretch using } \\
\text { strap }-45 \text { sec. } \times 2 \text { daily. } \\
\text { 3. Single heel raises, } \\
\text { performed bilaterally } 1 \times 10 \\
\text { track days }\end{array}$ & $\begin{array}{l}\text { 1. DF stretch on step }-30 \\
\text { sec. } \times 2 \text { daily } \\
\text { 2. Eversion stretch using } \\
\text { strap }-45 \text { sec. } \times 2 \text { daily. } \\
\text { 3. Single heel raises, } 2 \times 10 \\
\text { track days }\end{array}$ & $\begin{array}{l}\text { 1. DF stretch on step }-45 \\
\text { sec. } x 2 \text { daily. } \\
\text { 2. Eversion stretch using } \\
\text { strap }-45 \text { sec. } x 2 \text { daily. } \\
\text { 3. Single heel raises, } 3 \times 10 \\
\text { track days } \\
\text { 4. Jump rope }-50 \text { reps track } \\
\text { days }\end{array}$ & $\begin{array}{l}\text { 1. DF stretch on step }-45 \mathrm{sec} \text {. } \\
\mathrm{x} 2 \text { daily. } \\
\text { 2. Eversion stretch using } \\
\text { strap }-45 \text { sec. } \text { x } 2 \text { daily. }\end{array}$ \\
\hline Run Training & $\begin{array}{l}3 \text { miles Mon, Thurs. } \\
\text { Long run of } 5 \text { miles Sat. }\end{array}$ & $\begin{array}{l}4 \text { miles Mon, Thurs. } \\
\text { Long run of 7-8 miles Sat. }\end{array}$ & $\begin{array}{l}5 \text { miles Mon, Thurs. } \\
\text { Long run of } 12 \text { miles Sat. }\end{array}$ & $\begin{array}{l}6 \text { miles Mon, Thurs. } \\
\text { Long run of 16-18 Sat. }\end{array}$ & $\begin{array}{l}3 \text { miles Mon, Thurs. } \\
\text { Long run of } 8 \text { miles Sat. }\end{array}$ \\
\hline
\end{tabular}

*Barefoot run training was performed as part of run mileage on weekday runs during week 1, 2, and 5. Patient would run 2.5 miles, for example in Week 1 and then perform 2 laps or .5 miles of barefoot run training at track. In weeks 3 and 4 barefoot training was performed on alternate days.

patient complained of no pain in the area of the fibula with running, and exhibited negative findings with vibration testing, we felt compelled to assist this patient in meeting her goal. Additionally, it was felt that reducing the joint limitations present and correcting her running form would further reduce stress on the fibula [31], allowing the patient to continue training as her stress fracture was continuing to heal.

The primary goal in regard to correcting her running form was to increase cadence and eliminate heel striking, which has been shown to significantly reduce stress on the lower extremities and improve running economy $[14,31]$.

The primary goal in regard to joint mobilization was to improve sub-talar eversion and talocrual dorsiflexion, thus improving the ability to pronate, thereby allowing the foot to absorb shock more effectively. It is well known that a pronated foot is a "mobile adapter", whereas a supinated foot is a "rigid lever" [32]. We hypothesized that by improving dorsiflexion and eversion, pronation would be able to occur more effectively, reducing stiffness in the lower extremity and improving its ability to absorb shock. We theorized that this may help protect the fibula from further damage. Additionally, this would assist the patient in reducing risk of injury in the future [11].

\section{Outcomes}

The patient in our case study met all goals established at initial evaluation, including the patient's goal of completing the Chicago Marathon. One week after the marathon the patient returned for a follow-up visit and exhibited negative findings on all special tests and scored $80 / 80$ on the LEFS. Additionally, the patient was seen at a running clinic 4 months after completing the marathon and while training for a second marathon and was still pain-free with running and all leisure activities.

At the conclusion of physical therapy, she demonstrated significant improvement in objective findings and was able to run without pain. Score on the LEFS increased from 46/80 to 80/80 (Table 1). Dorsiflexion and eversion ranges of motion were equal to the uninvolved side. Single leg stance time increased to 60 seconds with eyes open and 35 seconds with eyes closed. Running cadence increased from 78 strides per minute to 86 strides per minute and she was exhibiting a midfoot striking pattern during initial contact versus the heel striking she demonstrated during the initial evaluation.

\section{Discussion}

The most commonly prescribed treatment modality in the case of stress fracture is rest [28]. Many different modalities, in addition to rest, are used to assist in the recovery from stress fracture [33-35]. This case is unique in that the patient refrained from rest, but was able to recover fully without re-injury. Granted, allowing this patient to continue running despite evidence of stress fracture was risky. It was evident, however, from the first visit that this patient was going to run regardless of what advice she was given. We explained the potential risks of attempting to train before sufficient time had passed for full fracture healing.

Average time necessary for modification of activity to allow for healing of fibular fractures is 4-6 weeks and can be complicated by several factors such as age and osteoporosis [36]. This patient was 4 weeks from diagnosis at time of her initial evaluation, within the 4-6 week window of time. Additionally, she exhibited no factors that may complicate healing time, such as mechanical stress, smoking and NSAID use $[37,38]$. These factors coupled with the fact that vibration testing was not provocative and she was running at reduced effort without pain, we were willing to be more aggressive as she was only 6 weeks out from the marathon. We felt it was imperative to reduce loading on the fibula as much as possible to avoid further complicating the healing process.

One way of reducing stress on the lower extremities during running is through bodyweight supported treadmill training [39]. These treadmills have been used by elite runners to allow them to continue running through such injuries as stress fracture. We did not have this equipment at our disposal so this was not an option for our patient. Another alternative would have been water running, but the patient was unwilling to do this. Because of our experiences with barefoot running, we felt training in this manner for short distances may create the changes in running form we were looking for without causing further harm.

Barefoot running by nature induces a mid-foot to forefoot striking pattern versus heel striking pattern [16]. Barefoot running also reduces loading on the joints of the lower extremity [40], because of the shift from a heel strike to mid to forefoot strike. We were hopeful that by inducing these changes in her running form, we could keep her running while minimizing stress on the fibula at the same time. Barefoot running can be implemented easily without need for special equipment or feedback [41]. This allows for more automatic change in running technique.

We were skeptical at the prospect of her being able to train through this injury. However, the patient had a substantial reduction in pain from visits 1-2 which allowed us to progress her rehabilitation more quickly and aggressively than anticipated. This was largely due to 
the effectiveness of manipulating the sub-talar and talocrural joints. As demonstrated by Lopez-Rodriguez, et al., manipulation of the talocrural joint can have immediate effects [42]. We noted significant improvement in sub-talar and talocrural joint mobility with restrictions being only minimal after treatment as compared to moderate prior to treatment. The patient reported that she felt less discomfort and freer motion in the ankle almost immediately, allowing her to run 2 miles at nearly $100 \%$ effort without pain the evening of her first visit. As described earlier, greater range of joint excursion reduces loading on the lower extremity [11]. This patient demonstrated significant improvement in range of motion as a result of joint mobilization. No stretching was performed during the first visit, nor therapeutic exercise, therefore, we attribute the significant improvement in joint range of motion to joint mobilization techniques and no other intervention. The increase in motion may indeed have reduced loading on the lower extremity, which is why the injury did not slow her progression and she could increase her running volume more aggressively than would be recommended.

It is typically felt that increases of no more than $10-25 \%$ in training volume should be made from one week to the next [43]. In fact, abrupt changes in exercise volume have been shown to contribute to injury [43]. The increases in training volume from weeks $2-4$ were obviously well beyond the recommended ranges. Our reasons for doing this were twofold. One, we wanted the patient to be able to have a "rebuild" period since she had missed training time. Two, we wanted to severely test the left lower extremity to insure it was able to withstand the rigors of what the patient was about to attempt. We also felt that if re-injury were to occur, we preferred for it to happen well before the marathon and in relatively controlled conditions as should issues arise during the race, we were fearful that she would push through and ignore them causing serious damage. Given that she was able to complete such a significant increase in volume without incident made us comfortable with her traveling to Chicago and attempting the marathon.

Despite this significant improvement, we still felt it imperative to progress barefoot run training as we felt her running form could be a contributing cause of injury. In fact, typical running form in the modern running shoe has been shown to increase torques at the ankle, knee and hip [44]. We felt adapting barefoot running technique and shifting to more of a mid-foot strike with increased stride rate would help reduce these torques and thus injury risk [15]. Additionally, barefoot running has shown to improve running economy [11]. We saw similar results as this patient was able to increase her cadence by nearly $10 \%$ throughout training. Based on the findings of Heiderscheidt, et al. [31], these changes in cadence are reflective of improvements in running economy as they showed improvement with increases in running cadence of as little as 5\% [31].

This case study demonstrates a novel approach to rehabilitation of a fibular stress fracture in a distance runner. It is plausible that this runner was able to rehabilitate so well because her fracture was very focal and caught at an early stage. She was also very fit and slightly built which may have allowed her to adapt barefoot running techniques more readily, as this in itself can be very difficult and in some cases lead to injury [45]. Careful selection of appropriate patients must be employed as this running style may not benefit weakened foot structures until sufficient time is allowed for adaptation by the muscles and ligaments [44]. Fortunately, this patient was able to adapt these techniques without incurring muscle strain or injury.

This case also demonstrates how committed and motivated some athletes are in achieving their goals; even if achieving that goal may be putting their health at risk. This is a factor that must not be overlooked as subjective report may not be accurate. One must be careful that the athlete isn't merely saying they are okay, when actually pain is present. That is why this patient was reassessed so regularly and objective measures were used to determine appropriateness for progression, not simply patient report.

As this case demonstrates, barefoot running may be an effective treatment strategy in rehabilitating runners. Research on its effectiveness in various conditions and with a large cohort of runners is necessary before conclusions can be drawn as this case only describes one runner with a very specific injury. Nonetheless, we have shown that barefoot running as a treatment modality in combination with manual therapy techniques may be effective in treating fibular stress fracture.

\section{Conflicts of interest}

The author certifies that he or she has no commercial associations (e.g., consultancies, stock ownership, equity interest, patent/licensing arrangements, etc.) that might pose a conflict of interest in connection with the submitted article."

\section{Ethical review board}

IRB exempt (case report).

\section{References}

1. Hulkko A, Orava S (1987) Stress fractures in athletes. Int J Sports Med 8: 221-226. [Crossref]

2. Fredericson M, Jennings F, Beaulieu C, Matheson GO (2006) Stress fractures in athletes. Top Magn Reson Imaging 17: 309-325. [Crossref]

3. van Mechelen W (1992) Running injuries. A review of the epidemiological literature. Sports Med 14: 320-335. [Crossref]

4. Cavanagh PR, Lafortune MA (1980) Ground reaction forces in distance running. $J$ Biomech 13: 397-406. [Crossref]

5. Farley CT, González O (1996) Leg stiffness and stride frequency in human running. $J$ Biomech 29: 181-186. [Crossref]

6. McBryde AM Jr (1985) Stress fractures in runners. Clin Sports Med 4: 737-752. [Crossref]

7. Reinker KA, Ozburne S (1979) A comparison of male and female orthopaedic pathology in basic training. Mil Med 144: 532-536. [Crossref]

8. Bennell KL, Malcolm SA, Thomas SA, Ebeling PR, McCrory PR, et al. (1995) Risk factors for stress fractures in female track-and-field athletes: a retrospective analysis. Clin J Sport Med 5: 229-235. [Crossref]

9. Milner CE, Ferber R, Pollard CD, Hamill J, Davis IS (2006) Biomechanical factor associated with tibial stress fracture in female runners. Medicine \& Science in Sports \& Exercise 38: 323-328.

10. Neely FG (1998) Biomechanical risk factors for exercise-related lower limb injuries. Sports Med 26: 395-413. [Crossref]

11. Dugan SA, Bhat KP (2005) Biomechanics and analysis of running gait. Phys Med Rehabil Clin N Am 16: 603-621. [Crossref]

12. Franco AH (1987) Pes cavus and pes planus. Analyses and treatment. Phys Ther 67 688-694. [Crossref]

13. Cook SD, Brinker MR, Poche M (1990) Running shoes. Their relationship to running injuries. Sports Med 10: 1-8. [Crossref]

14. Hanson NJ, Berg K, Deka P, Meendering JR, Ryan C (2011) Oxygen cost of running barefoot vs. running shod. Int J Sports Med 32: 401-406. [Crossref]

15. Robbins SE, Hanna AM (1987) Running-related injury prevention through barefoot adaptations. Med Sci Sports Exerc 19: 148-156. [Crossref]

16. De Wit B, De Clercq D, Aerts P (2000) Biomechanical analysis of the stance phase during barefoot and shod running. J Biomech 33: 269-278. [Crossref]

17. Munro CF, Miller DI, Fuglevand AJ (1987) Ground reaction forces in running: a reexamination. J Biomech 20: 147-155. [Crossref] 
18. RJ (2001) Guide to physical therapist practice 2nd, ed. Phys Ther, 81: 9-744.

19. Paris S (2000) A history of manipulative therapy through the ages and up to the current controversy in the United States. Journal of Manual \& Manipulative Therapy 8: 66-77.

20. Green T, Refshauge K, Crosbie J, Adams R (2001) A randomized controlled trial of a passive accessory joint mobilization on acute ankle inversion sprains. Physical Therapy 81: 984-994. [Crossref]

21. Pellow JE, Brantingham JW (2001) The efficacy of adjusting the ankle in the treatment of subacute and chronic grade I and grade II ankle inversion sprains. J Manipulative Physiol Ther 24: 17-24

22. van der Wees PJ, Lenssen AF, Hendriks EJ, Stomp DJ, Dekker J, de Bie RA (2006) Effectiveness of exercise therapy and manual mobilisation in ankle sprain and functional instability: a systematic review. Aust J Physiother 52: 27-37. [Crossref]

23. Cleland J (2005) Orthopaedic clinical examination: an evidence based approach for. Icon Learning Systems.

24. Kendall F, McCreary EK (1983) Muscles: Testing and Function (3rd ed.). Lippincott Williams and Wilkins.

25. Hengeveld E, Banks K (2005) Maitland's peripheral manipulation. Elsevier/ Butterworth Heinemann.

26. Dissmann PD, Han KH (2006) The tuning fork test-a useful tool for improving specificity in "Ottawa positive" patients after ankle inversion injury. Emerg Med $J$ 23: 788-790. [Crossref]

27. Binkley JM, Stratford PW, Lott SA, Riddle DL (1999) The lower extremity functional scale (LEFS): Scale development, measurement properties, and clinical application. Phys Ther 79: 371-383. [Crossref]

28. Raasch WG, Hergan DJ (2006) Treatment of stress fractures: the fundamentals. Clin Sports Med 25: 29-36. [Crossref]

29. Takebe K, Nakagawa A, Minami H, Kanazawa H, Hirohata K (1984) Role of the fibula in weight-bearing. Clin Orthop Relat Res 289-292. [Crossref]

30. Wang Q, Whittle M, Cunningham J, Kenwright J (1996) Fibula and its ligaments in load transmission and ankle joint stability. Clin Orthop Relat Res 261-270. [Crossref]

31. Heiderscheit BC, Chumanov ES, Michalski MP, Wille CM, Ryan MB (2011) Effects of step rate manipulation on joint mechanics during running. Med Sci Sports Exerc 43: 296-302. [Crossref]
32. Marshall P (1988) The rehabilitation of overuse foot injuries in athletes and dancers Clin Sports Med 7: 175-191. [Crossref]

33. Dickson TB Jr, Kichline PD (1987) Functional management of stress fractures in female athletes using a pneumatic leg brace. Am J Sports Med 15: 86-89. [Crossref]

34. Benazzo F, Mosconi M, Beccarisi G, Galli U (1995) Use of capacitive coupled electric fields in stress fractures in athletes. Clin Orthop Relat Res 145-149. [Crossref]

35. Walker NA, Denegar CR, Preische J (2007) Low-intensity pulsed ultrasound and pulsed electromagnetic field in the treatment of tibial fractures: A systematic review. $J$ Athl Train 42: 530-535. [Crossref]

36. Augat P, Simon U, Liedert A, Claes L (2005) Mechanics and mechano-biology of fracture healing in normal and osteoporotic bone. Osteoporos Int 16 Suppl 2: S36-43. [Crossref]

37. Ha KI, Hahn SH, Chung MY, Yang BK, Yi SR (1991) A clinical study of stress fractures in sports activities. Orthopedics 14: 1089-1095. [Crossref]

38. Bennell K, Brukner P (2007) How should you treat a stress fracture? Evidence-based Sports Medicine 538-561

39. Martin J, Plummer P, Bowden M, Fulk G, Behrman A (2006) Body weight support systems: considerations for clinicians. Physical Therapy Reviews 11: 143-152.

40. Divert C, Mornieux G, Freychat P, Baly L, Mayer F, Belli A (2008) Barefoot-shod running differences: shoe or mass effect? Int J Sports Med 29: 512-518. [Crossref]

41. Hart PM, Smith DR (2008) Preventing running injuries through barefoot activity. Journal of Physical Education, Recreation \& Dance 79: 1-60.

42. López-Rodríguez S, Fernández de-Las-Peñas C, Alburquerque-Sendín F, RodríguezBlanco C, Palomeque-del-Cerro L (2007) Immediate effects of manipulation of the talocrural joint on stabilometry and baropodometry in patients with ankle sprain. $J$ Manipulative Physiol Ther 30: 186-192. [Crossref]

43. Almeida SA, Williams KM, Shaffer RA, Brodine SK (1999) Epidemiological patterns of musculoskeletal injuries and physical training. Med Sci Sports Exerc 31: 1176-1182. [Crossref]

44. Kerrigan DC, Franz JR, Keenan GS, Dicharry J, Della Croce U, Wilder RP (2009) The effect of running shoes on lower extremity joint torques. $P M R$ 1: 1058-1063. [Crossref]

45. Giuliani J, Masini B, Alitz C, Owens BD (2011) Barefoot-simulating Footwear Associated With Metatarsal Stress Injury in 2 Runners. Orthopedics 34: 550. [Crossref]

Copyright: $\odot 2017$ Clark BB. This is an open-access article distributed under the terms of the Creative Commons Attribution License, which permits unrestricted use, distribution, and reproduction in any medium, provided the original author and source are credited. 